\title{
VACACIONES EN LA NATURALEZA: REFLEXIONES SOBRE EL ORIGEN, TEORÍA Y PRACTICA DEL ECOTURISMO
}

\author{
Esther GIL ÁLVAREZ \\ Universidad de Valladolid
}

\begin{abstract}
RESUMEN: Este artículo pretende reflexionar sobre el marco teórico y metodológico que inspira el turismo en los espacios naturales (Ecoturismo). Con estos fines, se analiza el contexto explicativo que da sentido y permite entender el auge de los turismos alternativos, insistiendo en las tipologías relacionadas con el "turismo verde" o Ecoturismo, del que se profundiza en su definición, estructura de mercados, así como en algunas de las principales técnicas comúnmente aplicadas en materia de planificación y gestión.
\end{abstract}

$\boldsymbol{P A L A B R A S ~ C L A V E}$ : Ecoturismo, desarrollo sostenible, mercado de ecoturismo, espacios naturales protegidos.

ABSTRACT: This article aims to analyse the theoretical ando methodological context that is in the based of tourism in natural spaces (Ecotourism). With this purpose, the context explaining with the new alternative tourist models is analysed, we will insist on typologies related to "Green Tourism" or "Ecotourism". We will analyse its definition, market structures, as well as some of the main techniques usualy commonly applied concerning planning and management.

KEY WORDS: Ecotourism, sustainable development, ecotourism market, natural reserves.

RÉSUMÉ: Cet article essaie de réfléchir au contexte théorique et méthodologique qu'inspire le tourisme des zones naturelles (Écotourisme). À ces effects, le contexte explicatif des nouveaux modèles du tourisme alternatifs est analysé, en insistant dans les typologies liés au "tourisme vert" ou lécotourisme, dont est approfondi dans sa définition, sdtructure de marché, aussi bien que dans quelques-unes des principales techniques communément apliqueés en matière de planification et gestion.

MOTS-CLÉS: L’écotourisme, développment durable, marché de l'écotourisme, espaces naturels protégés.

RESUMO: Neste artigo pretendemos reflexionar sobre marco teórico e metodológico que inspira o turismo nos espaços naturais (Eco-turismo). Com esta finalidade, analisa-se o contexto explicativo que da o sentido e permite entender o auge do turismo alternativo, insistindo na tipologia relacionada com o "turismo verde" ou Eco-turismo, do que aprofunda na sua definição, estrutura de mercados, assim como nalgumas das principais técnicas comumente aplicadas na sua planificação e gestão.

PALAVRAS CHAVE: Eco-turismo, desenvolvimento sustenido, mercado de eco-turismo, espaços naturais protegidos.

\section{I. ¿INTRODUCCIÓN?}

Una aproximación teórica a las características que presenta el turismo en los espacios naturales obliga a integrar esta temática en el marco de las nuevas orientaciones basadas en el desarrollo de fórmulas turísticas alternativas, surgidas desde mediados de los ochenta como respuesta a la situación de crisis e in- 
certidumbre experimentada por el turismo de masas o modelo turístico convencional en las sociedades desarrolladas. Dicho de otro modo, se trata de enmarcar la práctica del turismo en el contexto de la irrupción de nuevas modalidades basadas en el aprovechamiento "sostenible" de entornos de carácter rural y natural, lo que ha supuesto el auge del denominado, de forma genérica y globalizadora, Ecoturismo, aunque con un sentido similar se utilicen con frecuencia otros vocablos como Turismo Verde o Sostenible, Turismo de la Naturaleza, Turismo Activo, Turismo Rural, Turismo Ecológico, Turismo de Aventura, Turismo de Escaso Impacto, Turismo Blando, etc....creando en ocasiones una cierta confusión terminológica. El denominador común de estos turismos es doble y tiene que ver, por un lado, con una ubicación física en espacios de carácter rural y/o natural; y por otro, con la práctica de un tipo de actividades asociadas a un concepto de ocio o de vacaciones activas. Se hace referencia, por tanto, a nuevas prácticas turísticas, vinculadas, indistintamente, si bien con ciertos matices y diferenciaciones entre ellas, a condiciones como "ecológico" y "activo".

Desde esta perspectiva, las páginas que siguen se centran básicamente en el análisis y comentario de los siguientes aspectos: en primer lugar, y con el propósito de ofrecer un marco interpretativo global, se profundiza en los fundamentos explicativos de estas nuevas modalidades, lo que supone insistir tanto en los factores coyunturales, relacionados básicamente con la "crisis del modelo turístico de sol y playa" y el declive del mundo rural en los países desarrollados, como muy especialmente en los planteamientos ideológicos y políticos que les sustentan y sirven de soporte. Como se verá, el ecoturismo está estrechamente conectado con los valores y la filosofía del ecologismo y, relacionado con esto mismo, con el concepto de "conservación" lo que supone profundizar en aspectos clave como la "sostenibilidad" y la planificación y el "desarrollo sostenible" como principios fundamentales en los que se apoya, al menos desde un punto de vista ideológico, la teoría y la práctica de las vacaciones en la naturaleza; en un estadio posterior, se pasa a identificar y definir con mayor precisión y claridad el concepto de Ecoturismo y sus rasgos diferenciadores, para a continuación centrarnos en el análisis del mercado de este tipo de turismo, atendiendo a las peculiaridades de su oferta y demanda. En este contexto, se realiza un desglose pormenorizado de las distintas posibilidades de tipo deportivorecreativo y de animación socio-cultural inherentes a la práctica del Ecoturismo (condiciones de oferta), así como de las motivaciones y características que singularizan a los nuevos tipos de consumidores ("ecoturistas").

El artículo finaliza realizando una referencia explícita a la vinculación del turismo con un tipo de espacios naturales específicos, a saber, los espacios naturales protegidos. Con estos fines, se comentan las peculiaridades inherentes a este tipo de entornos y se hace un breve repaso de las técnicas de gestión habitual- 
mente utilizadas en aras a compatibilizar y lograr el difícil equilibrio entre la utilización de los recursos con finalidad turística y su conservación y mantenimiento.

\section{LOS FUNDAMENTOS DEL TURISMO EN LOS ESPACIOS NATURALES Y RURALES.}

Es sabido que el medio natural constituye una de las bases del desarrollo y de la localización del turismo, actuando tanto como soporte fisico sobre el que se diseñan y se ubican las distintas actividades, como factor de atracción de los flujos turísticos. Así se ha explicado tradicionalmente el auge experimentado por el turismo convencional o turismo de masas, identificado principalmente con las modalidades asociadas al modelo turístico de sol y playa en los espacios litorales, y al turismo de nieve o blanco, en las áreas interiores o de montaña, cuyo funcionamiento se ha basado en el aprovechamiento intensivo de determinados recursos naturales.

Va a ser precisamente el carácter intensivo de la explotación de estos recursos, unido a patrones de aprovechamiento y modelos de implantación territorial en muchas ocasiones agresivos con el medio natural y cultural, una de las razones fundamentales en la explicación de la situación de crisis y deterioro de la competitividad que experimenta el turismo convencional, al constatarse sus numerosas deficiencias e inconvenientes, en particular por lo que se refiere al turismo de sol y playa.

A este respecto, tanto la Organización Mundial del Turismo como numerosos expertos han destacado las singularidades pero también las rigideces de un modelo concebido y ofertado a gran escala, concentrado desde el punto de vista de la oferta (grandes cadenas hoteleras en EEUU, tour-operadores en las costas mediterráneas europeas ) y masificado desde la perspectiva de la demanda (saturación de espacios), con un escaso, por no decir nulo, interés en la conservación y desarrollo de los recursos naturales y culturales del interior (patrimonio dormido), cuyas consecuencias pueden contemplarse desde tres perspectivas diferentes y complementarias entre sí: por un lado, y desde el punto de vista del propio turista, proporciona una imagen incompleta, y en todo caso sesgada, del país visitado y se basa en la oferta de actividades de esparcimiento poco o nada creativas (tumbarse al sol, salir de copas, shopping, consumismo,etc.. ) generando un modelo de turista pasivo. Por otro lado, y desde la óptica de la comunidad receptora, genera pocos beneficios directos, acaparados por las grandes cadenas de hoteles y restaurantes, si bien hay que reconocer que crea riqueza y empleo, pero con importantes contrapartidas sociales y ambientales (ruidos, molestias, invasión desmesurada de visitantes, colonización de espacios, saturación, congestión, etc..). Finalmente, y por lo que tiene que ver con los efectos 
sobre el entorno natural y cultural, la aplicación de este modelo ha traído consigo no pocas veces un inevitable deterioro del paisaje y del medio ambiente, y lo que es peor, una pérdida de su autenticidad, al permitir una brutal transformación de municipios y espacios, de manera que es imposible reconocerlos tal y con lo que eran en el pasado (BOTE,1988;CAMISÓN, 1996; OMT, 1998) ${ }^{1}$.

A todo ello, y de manera especialmente relevante, deben añadirse los efectos que, sobre la evolución del sector en los destinos turísticos tradicionales de sol y playa, han tenido los cambios estructurales del entorno económico mundial en las últimas décadas, especialmente desde finales de los ochenta, y que se han traducido en alteraciones de las tasas y niveles de crecimiento anteriores, con una clara tendencia a la moderación e incluso al estancamiento, induciendo estrategias de reestructuración y favoreciendo el desarrollo de productos turísticos alternativos (OMT, 1998).

A modo de síntesis, este conjunto de cambios se relacionan fundamentalmente con los siguientes aspectos: de un lado, la intensificación de los procesos de globalización en cuanto a áreas receptoras, a medida que se contraen los espacios de conexión, por efecto de las mejoras en la accesibilidad y el abaratamiento de los costes del transporte, y que permite incorporar nuevas periferias como destinos turísticos en el panorama internacional, (Caribe, Sudeste Asiático, Oceanía- "la cuarta periferia" de GORMSEN (1981), con ventajas comparativas (exotismo, calidad ambiental, precios más baratos, etc..) y en definitiva, se traduce en un endurecimiento de las condiciones de la competencia. Por otro lado, y en un contexto socio-económico internacional marcado por la transición de la Sociedad Industrial a la Sociedad Informacional (CASTELLS, M.,1997) los efectos del cambio tecnológico y sus implicaciones en aspectos como el aumento del tiempo de ocio (vacaciones) y su flexibilización (más y divididas en periodos más cortos) generan alteraciones tanto en los modos de diseñar y gestionar la oferta (nuevas formas de producción más flexibles e informatizadas), como en los gustos de los consumidores (auge de los productos turísticos de duración corta -fines de semana, puentes, etc..-). Una demanda, por otro lado, cada vez más exigente y sofisticada, en la que se observan además nuevas preferencias concretadas en un mayor interés y sensibilidad por el medio ambiente y contacto con la naturaleza, en un contexto de desarrollo del ecologismo como para-

\footnotetext{
${ }^{1}$ El sector turístico se ha caracterizado tradicionalmente por ofrecer vacaciones estandarizadas a turistas inexpertos, caracterizados por motivaciones muy básicas (sol y playa) a precios bajos. El paradigma de la productividad en masa del sector industrial, basado en economías de escala y la estandarización fue adoptado por el sector turístico, generando la producción de paquetes turísticos rígidos, controlados por grandes touroperadores y mayoristas, que permiten mantener costes de producción reducidos a fin de ofrecérselos a turistas para quienes la calidad del producto consumido importaba menos que el precio (OMT, 1998, 381).
} 
digma proyectable sobre todos los ámbitos de la vida y consolidación de la cultura ambiental, a lo que no es ajeno el mayor nivel educativo y cultural de la población. Y relacionado con esto, una mentalidad mayoritaria caracterizada por una mayor preocupación por la salud y la forma física, una búsqueda de lo auténtico, de lo natural, de lo ecológico y, en definitiva, una conciencia cada vez más extendida de cansancio hacia las formas de vida urbanas caracterizadas por la agitación, el desasosiego y la aparición del estrés como elemento inseparable de la jornada laboral, todo lo cual induce nuevos comportamientos, nuevas preferencias y actúa como catalizador de la diversificación del producto turístico, impulsando los turismos alternativos, y muy especialmente todas las tipologías relacionadas con el turismo "verde"

Todo este proceso obliga a cuestionar y revisar los planteamientos tradicionales e induce a administraciones y agentes privados del sector a plantear nuevas líneas de actuación y reestructuración orientadas a crear ventajas competitivas y recuperar los niveles de rentabilidad sobre la vía de la calidad, la eficiencia, la innovación y la sostenibilidad ${ }^{3}$. Con todo, y como afirma Gabilondo, no se plantea la inviabilidad del modelo de sol y playa, producto estrella de los destinos maduros, y todavía más en los ámbitos emergentes (Caribe, Sudeste Asiático, etc...), sino la necesidad de su reestructuración y de su inclusión en un con-

\footnotetext{
${ }^{2}$ Poon identifica cinco fuerzas fundamentales que impulsan el cambio y su transición hacia lo que Fayos identifica como La Nueva Era del Turismo: nuevos consumidores, nuevas tecnologías, necesidad de nuevas formas de producción y gestión más flexibles y cambios en el entorno. La transformación del turismo se dirige hacia formas distintas de organización y gestión, para lograr una mayor productividad y efectividad, a través de los principios de calidad, flexibilidad, desarrollo integrado en el entorno, atención personalizada al cliente, innovación e integración diagonal (PoON,1993,94).Las nuevas características y condiciones configuran un paradigma empresarial distinto al que Fayos denomina la Nueva Era del Turismo definido, en esencia, por cinco aspectos: vacaciones flexibles y a precios más competitivos; producción más personalizada de los servicios turísticos; marketing dirigido hacia nichos específicos de mercado, con diferentes necesidades, intereses, etc...; consumidores más experimentados y con necesidades más complejas, que consideran el entorno y la cultura local como parte de la experiencia turística; nuevas tecnologías de la información y comunicación al servicio de la actividad turística (flexibilidad) (FAYOS, 1994).

${ }^{3}$ Se trata, en definitiva, de superar las rigideces del modelo, lo que supone definir nuevas estrategias desde una dimensión territorial y ambiental que comportan, entre otros aspectos, la redefinición del modelo de reestructuración de áreas degradadas, la protección y recuperación del entorno natural y urbano, la opción por nuevas tipologías urbanísticas acordes con el contexto paisajístico y la inserción de otros elementos de oferta capaces de cualificar y diversificar el producto convencional y rutinario entre otras líneas de intervención. Para un estudio exhaustivo sobre las nuevas tendencias turísticas y las estrategias de reordenación de los espacios turísticas tradicionales véase VERA, F. (coord., 1997, 98-122).
} 
texto en el que la actividad turística adquiere dimensiones de complejidad cada vez más amplias ${ }^{4}$.

La situación de incertidumbre y deterioro de la competitividad del modelo turístico de sol y playa, se ve agravada por la coincidencia en el tiempo de otro factor coyuntural de gran trascendencia en los países desarrollados europeos, relacionado con la situación de decadencia en que se ve inmerso el espacio rural, sometido a una serie de cambios que vienen a sumirlo en una profunda crisis, máxime en España donde la extensión de sus espacios rurales y el porcentaje tradicional de población dedicada a la actividad agraria ha sido tradicionalmente muy elevado.

Estos cambios se relacionan básicamente con los efectos asociados a la mecanización del campo y a la aplicación de la política agraria comunitaria (P.A.C) y su pretendida disminución de los excedentes agrarios, lo que ha supuesto, entre otras consecuencias, un éxodo rural enorme, una disminución espectacular de la población agraria y su envejecimiento masivo a partir del momento de su aplicación. Esta situación hace que una cantidad creciente de agricultores y propietarios se vea obligada a buscar con rapidez vías de diversificación y soluciones alternativas o complementarias a sus ocupaciones tradicionales. De ahí el interés de las Administraciones Públicas en potenciar aquellas actividades que permitan generar nuevas fuentes de recursos y trabajo en el medio rural-natural, tratando de diversificar la economía rural con otras actividades distintas a la puramente agraria. Va a ser precisamente esta tarea, el apoyo público al turismo alternativo, otro de los elementos claves en la explicación del auge de los nuevos productos turísticos, concretamente el Turismo Rural y el Ecoturismo, entendidos ambos en sentido amplio, aprovechando, por otra parte, las nuevas demandas urbanas de ocio dirigidas hacia el campo y el contacto con la naturaleza, que están en la base de la apuesta por los turismos alternativos como estrategia de desarrollo indiscutible por parte de los poderes públicos (LEADER,1996).

En este contexto, la estrategia tradicional del sol y la playa comienza a ser parcialmente sustituida o complementada por otras alternativas de carácter más "ecológico" o "artesanal" (turismo verde, turismo rural, turismo de salud, turismo de deporte y aventura, etc...), todas ellas caracterizadas en "teoría" por su respeto hacia el medio ambiente (desarrollo sostenible), carácter difuso o no concentrado (pequeña escala), basadas en una oferta integrada de ocio (turistas

\footnotetext{
${ }^{4}$ Por ello, y con independencia de las nuevas tendencias, no deja de ser un hecho claro que los flujos turísticos hacia las regiones litorales de sol y playa, en su conjunto, sigan aumentando, si bien el análisis pormenorizado pone de manifiesto contrastes internos (GABILONDO, 1996).
} 
activos) y con implicación explícita de la comunidad local, tanto desde el punto de vista de la gestión, de la planificación, de las iniciativas, como de los costes y de los beneficios. Es en la correcta implementación de este tipo de turismos alternativos donde se vislumbran numerosas bondades o efectos benéficos, pues en sus rasgos distintivos se observa una gran potencialidad para el desarrollo de aspectos valorados críticamente en el turismo tradicional, al permitir un mayor enriquecimiento personal y cultural del visitante, una efectiva recuperación de sus energías físicas y mentales, un fomento de la cooperación y del intercambio de experiencias y de culturas entre la población local y la foránea, y lo que es más importante, una percepción auténtica y no deformada de la cultura local de la zona. Por otro lado, y en cuando a los efectos sobre los habitantes y las comunidades receptoras, una mayor toma de conciencia de la cultura propia, revalorizada y potenciada, un estímulo al desarrollo de áreas rurales-naturales en ocasiones muy desfavorecidas o de regiones atrasadas, etc. Finalmente, y en lo relacionado con las consecuencias ambientales, un instrumento perfecto para la conservación y protección del medio natural, la recuperación del patrimonio socio-cultural, etc... (BOTE, 1988; OMT, 1998).

De este modo, el sistema integrado Turismo-Ocio-Naturaleza comienza a perfilarse como una de las características de la Sociedad Post-Industrial y de la Nueva Era del Turismo. Con todo, conviene no olvidar que la frecuentación del campo y de los espacios naturales con fines recreativos es antigua, así como la concepción de los parques naturales como zonas de disfrute público. Sin embargo, ha sido a lo largo de los últimos años cuando se ha producido una popularización del turismo vinculado a la naturaleza y al mundo rural. (VERA, F., coord., 1997, 142). La innovación más sorprendente operada en el campo de lo que genéricamente podríamos llamar actividades turísticas y de ocio, al menos en lo referente a los países fuertemente desarrollados, es la que ya se denomina como "explosión" del turismo en espacios naturales o turismo "verde". Como vemos, esta realidad no es fruto de la mera coyuntura casual o reflejo de una moda pasajera, sino que resulta de la conjunción de una serie de factores de largo alcance que parecen irreversibles, al menos a corto y medio plazo (MARCHENA, 1992).

En el caso concreto de España, configurada desde los años 50 del siglo XX como destino turístico de primer orden, particularmente sus áreas litorales mediterráneas y sus archipiélagos insulares, su evolución ha presentado una dinámica similar al funcionamiento mostrado en los espacios del turismo de masas (BAYÓN, 1999; PELlEJERO, 1999)5. Así, las dificultades surgidas a finales de

\footnotetext{
${ }^{5}$ Aparte de los señalado sus puntos débiles se relacionan específicamente con: en primer lugar, una degradación de la calidad del producto turístico, especialmente en cuanto al entorno pai-
} 
los ochenta y primeros de los noventa en relación con la pérdida de calidad y deterioro de la imagen de España como destino turístico, motivaron la elaboración de medidas públicas como Libro Blanco del Turismo Español y otros similares en distintas CCAA con el propósito de redefinir el marco estructural del turismo en un escenario donde el liderazgo cuantitativo en captación de afluencia no se había acompañado de mejoras cualitativas y de la consolidación de una verdadera posición competitiva, con más alcance y futuro que la competencia por la vía de los bajos precios y elevados costes ambientales del sistema de explotación. Entre las nuevas líneas de trabajo, preocupa la regulación de los aspectos ambientales y territoriales en destinos consolidados (sol y playa) como la necesidad de sentar unas bases estructurales sólidas para los nuevos desarrollos que se están produciendo en áreas rurales, ciudades históricas y tramos no explotados del litoral desde la sostenibilidad como referencia. Las nuevas propuestas aparecen definidas en documentos como el Plan Marco de Competitividad del Turismo Español (PLAN FutURES, desde 1992) de la Secretaria de Espado de Turismo, el Plan Integral de Calidad del Turismo Español (PICTE 2000), el proyecto Municipio Verde (Ministerio de Medio Ambiente y Dirección General de Turismo) y propuestas de las distintas Comunidades Autónomas (Baleareas, Cataluña, Comunidad Valenciana, Andalucía, etc...) ${ }^{6}$.

Como consecuencia de los esfuerzos realizados, y pese a que la primacía del turismo de sol y playa sigue siendo una constante en nuestro país, copando un $70 \%$ del mercado, queda claro que, según los últimos datos del Banco de España y de asociaciones como Exceltur, las alternativas al turismo tradicional también se han ido consolidando y van progresivamente ganando terreno hasta el punto de que, tal y como se afirma en algunos medios, "tumbarse en la playa y disfrutar del sol ya no es suficiente para sostener el turismo en España". Así, las actividades relacionadas con el turismo en la naturaleza, rural, deportivo, cultural etc... se consolidan como opciones al tradicional sol y playa en un momento de cambio de hábitos de ocio y caída de ingresos ${ }^{7}$.

\footnotetext{
sajístico y a la calidad del servicio; por otro lado, un creciente deterioro de la relación calidadprecio frente a nuevos escenarios turísticos en el ámbito internacional como el Mediterráneo (Grecia, Túnez, etc...) y el Caribe (México, República Dominicana, etc..); en tercer lugar; una elevada obsolescencia de la planta hotelera; y en cuarto lugar, toda una serie de elementos relacionados con el insuficiente nivel profesional en el sector, la saturación de las infraestructuras y de los servicios públicos, la alta dependencia de los tour operadores y, muy especialmente, la elevada concentración temporal de la demanda, o lo que es lo mismo, la elevada estacionalidad de la actividad turística.

${ }^{6}$ Un análisis de las características del modelo turístico español y de las estrategias de reordenación puede verse en Gil Olcina y GómEZ MENDOZA (Coord., 2001: 545-571).

${ }^{7}$ Para más información véase Suplemento de El País de los Negocios, del Domingo día 22 de mayo de 2005 .Portada: «El nuevo turismo gana terreno» y páginas 5 y 6: «El otro lado del sol y
} 


\section{TURISMO EN ESPACIOS NATURALES: UNA ACTIVIDAD Y UNA FILOSOFÍA.}

De lo expuesto hasta ahora, parece evidente que el Ecoturismo o turismo en espacios naturales, además de los factores de diferente índole que están en la base de su creciente interés es, ante todo, un reflejo evidente, un efecto y una consecuencia de los cambios fundamentales que se han producido en la forma que tienen los seres humanos de ver y relacionarse con la naturaleza; unos cambios que, en líneas generales entroncan con la visión ecocéntrica (o "ecológica") del mundo, frente a la tradicional moral antropocéntrica. Ambos enfoques suponen concepciones muy diferentes, y a menudo concurrentes entre sí, en relación con el valor asignado al entorno natural, así como de las prácticas orientadas hacia ese mundo de la naturaleza, las turísticas, entre ellas (NEIL, J., WEARING, S. y OTROS, 1999: 37). En líneas generales, la visión antropocéntrica encaja con una ética del "uso" en tanto que la ecocéntrica supone una ética de la "naturaleza". Partiendo de la identificación realizada por GODFREY-SMITH (1980) entre "valor instrumental" o utilitario y "valor intrínseco" o por sí mismo como las dos formas fundamentales de evaluar el valor de las cosas en la sociedad occidental, puede hablarse de una ética del "uso" o enfoque predominante en el que la naturaleza se ve sobre todo como un conjunto de recursos que la humanidad puede utilizar con toda libertad para obtener objetivos específicos propios, y que constituye la esencia de la visión antropocéntrica; y una ética "de la naturaleza" que sostiene que las entidades no humanas tienen el mismo valor que la especie humana, y que a grandes rasgos resulta intrínseca y ecocéntrica.

La ética del "uso" parte de un punto de vista humano y es esta perspectiva unívoca la que se describe a menudo como antropocentrismo. La base última sobre la que se evalúa el valor en el mundo occidental es instrumental, ya que los seres humanos aparecen como la fuente de todo el valor, la medida de todas las cosas. Un planteamiento de estas características no permite asignarle a la naturaleza ningún valor intrínseco en sí misma y para sí misma, puesto que su único valor está en su capacidad de satisfacer las necesidades y los deseos de los seres humanos. Su precedente está en la obra del filósofo empirista John LOCKE (1632-1704), quien expresó de la forma más sucinta nuestra herencia moderna del mundo actual cuando afirmó que todo lo que hay en la naturaleza es desperdicio hasta que las personas lo transforman en cosas de valor utilizables (cf. Un ensayo referente a la comprensión humana, 1976). Es éste un espíritu que las sociedades occidentales han hecho suyo con un nada disimulado entusiasmo, sustituyendo ecosistemas vitales por infraestructuras - casas, ciudades,

la playa».

Polígonos. Revista de Geografía, 14 (2004); pp. 17-52 
industrias, carreteras, etc...- todo ello para el beneficio y disfrute exclusivo de la especie humana. Sin embargo, aparte de Locke, el antropocentrismo tiene una muy larga y arraigada tradición. Ha sido, en la práctica, la teoría diferenciada más profunda y más persistente de todas las tradiciones filosóficas, sociales y políticas occidentales desde la época de la Grecia clásica (Fuente: ÍDEM, 38).

Resulta complicado rebatir esta "moralidad antropocéntrica" y su ética del "uso". En este sentido, Godfrey-Smith diferencia cuatro tipos de categorías de uso que justifican el valor instrumental de la naturaleza: a) Las estéticas/espirituales (el argumento de la "catedral") según las cuales la naturaleza es valorada por su capacidad de proporcionar una renovación espiritual y gozo estético; b) Las biológicas y las relacionadas con la biodiversidad (el argumento del "silo"), según las cuales la naturaleza es valorada por su acopio de diversidad genética; c) Las científicas ( el argumento del "laboratorio") según las cuales la naturaleza es valorada por las posibilidades que ofrece para la investigación científica, y d) Las atléticas (el argumento del "gimnasio") según las cuales la naturaleza es valorada por las posibilidades que ofrece para el turismo y las actividades recreativas (GODFREY-SMITH W.,1980).

Sin embargo, durante estas últimas décadas ha surgido una filosofía ecocéntrica, que básicamente desafía la escalas de valor antropocéntricas y está estrechamente vinculada con los planteamientos del ecoturismo, al que sirve de soporte teórico. Se trata de una posición filosófica abierta que intenta reconocer el valor intrínseco y es holística, con sólidos fundamentos en los campos de la biología y de la ecología de la naturaleza y que rechaza la visión según la cual el mundo está dividido en partes que se excluyen mutuamente. Así pues, defiende que todas las cosas, ya sean vivas o inertes, están interconectadas. Transmite la creencia de que el mundo es una red de vida compartida por todos los seres que lo habitan.

Desde esta perspectiva ecocéntrica, se defiende la necesidad de una reforma fundamental en todos los ámbitos - una reevaluación de las instituciones sociales, económicas, y educativas y, en definitiva, una reorientación completa de la sociedad tal como la conocemos-. Un elemento esencial dentro de esta transformación de valores está en el reconocimiento de que la naturaleza puede existir por derecho propio, sin que ese derecho dependa de los beneficios que el hombre obtenga de ella. En este contexto, mantener la biodiversidad o la "red de la vida" sobre la Tierra resulta beneficioso no sólo para la especie humana sino para todas las especies.

Esta línea ideológica nos lleva a las ideas que rodean la "ecología profunda" una de las corrientes de pensamiento del ecocentrismo que se ha debatido más ampliamente. La ecología profunda, que empieza fundamentalmente con el filó- 
sofo noruego Arne NAESS (1912), fuertemente influido por la ecología y la filosofía de Spinoza (1632-1677) es una visión del mundo global que se basa en una concepción holística de la naturaleza en la que el ser humano, a través de su yo, se encuentra intrínsicamente conectado con todas las formas de vida. No existen auténticos límites que separen a la humanidad de la naturaleza (una sola ontología), por tanto no existe ningún punto en el que se acabe el "yo", el individuo, y empiecen las demás formas de vida. El yo engloba todo el planeta que nos rodea y la naturaleza se convierte en una extensión de nosotros mismos. Así pues, nos corresponde ahora respetar y estar al servicio de los intereses comunes de todas las especies. El reconocimiento de que mantenemos una relación de interdependencia con la vida y el valor intrínseco de otras cosas exige, desde el punto de vista de los ecologistas profundos, que reduzcamos el impacto que producimos sobre nuestro planeta, tomando sólo lo necesario para satisfacer nuestras necesidades vitales. Entre las iniciativas que se derivan de esta postura filosófica figuran no sólo "caminar sobre la tierra sin pisar fuerte" sino también otras acciones o iniciativas que, de forma respetuosa, intentan conseguir que cambien de opinión y de conducta aquellas personas que siguen creyendo en la falsa ilusión de que la realización personal se basa en dominar la naturaleza y transformarla para satisfacer nuestras propias necesidades.

La gestión ecocéntrica, en el caso del turismo, viene a reconocer que la ciencia y la tecnología modernas no pueden impedir el deterioro ambiental si persisten las tendencias actuales en cuanto al crecimiento económico y al uso de recursos, admitiendo asimismo que se necesita cambiar la filosofía humana, la política y la economía, si se quiere garantizar la existencia de una población turística (los visitantes) que mantenga un equilibrio con el entorno físico y social (los anfitriones). Además de esto, el ecocentrismo se puede considerar como una doctrina "comunitaria" (partidaria de la propiedad compartida) -una postura conservacionista que vuelve a insistir en la necesidad de poner límites macroambientales previos al crecimiento económico y que está a favor de un sistema socio-económico descentralizado (gestión local) o como una forma de "ecología profunda" que se sustenta en la noción de que la naturaleza tiene un valor intrínseco (y no instrumental) para las especies no humanas.

En este contexto ideológico, en consecuencia, se ha de destacar la vital importancia que tiene el ecocentrismo para el ecoturismo, especialmente y de forma determinante en el tema de la gestión. El ecocentrismo, en tanto que ha de guiar la gestión, plantea que las zonas naturales protegidas no se están conservando o protegiendo para nadie en concreto, sino que existen porque tienen valor en sí mismas y para sí mismas. Este planteamiento desafía a la visión que predomina más en el mundo de hoy, adoptada principalmente por economistas que se ocu- 
pan del campo de los recursos, y que apoya la idea de que el mundo no humano sólo tiene valor en la medida en que resulta valioso para los seres humanos.

El ecoturismo lleva pues implícita la interiorización de los valores, la filosofía y los planteamientos ecocentristas. Hablar de ecoturismo significa hablar de un tipo viajes en los que prime la "conservación", o mejor, se logre conciliar desarrollo y conservación de la naturaleza, mediante el diseño y aplicación de prácticas turísticas respetuosas con el medio ambiente.

El entorno natural desempeña un papel primordial en el ecoturismo que concentra la atención en los rasgos bióticos y abióticos. La conservación de los marcos naturales y la gestión sostenible/responsable de los recursos resulta por lo tanto esencial para la planificación, el desarrollo y la gestión del ecoturismo. Valentine llama la atención sobre la "interacción en dos direcciones" que se da entre el ecoturismo y el medio ambiente del que depende, y sugiere que una característica del ecoturismo es que, a la vez que contribuye a la conservación, ofrece la posibilidad de disfrutar de la naturaleza. Es decir, el ecoturismo supone identificar la naturaleza como la motivación principal para viajar, con el fin de adquirir más conocimientos acerca de ese entorno natural y concienciarse más sobre el papel del mismo. También supone asumir la idea de que la actividad debe contribuir de manera decidida a la conservación en la zona de destino o comunidad receptora. La planificación del ecoturismo se basa en las limitaciones de los recursos, ya que se desaprovecharán las oportunidades que ofrece el ecoturismo si se sobrepasa la capacidad de recuperación de una zona y la capacidad de absorción del impacto turístico de la comunidad que vive allí o si se alteran de forma significativa su biodiversidad y apariencia física (VALENTINE, P. S. 1991)

Esto supone que el ecoturismo está ligado al concepto de "sostenibilidad", o si se prefiere de "desarrollo sostenible", premisa fundamental que preside las actividades turísticas desde la perspectiva de la gestión y fundamento básico de los rasgos identificadores del ecoturismo, al menos, y como se remarcará más adelante, desde un punto de vista teórico-conceptual.

\section{Un turismo sostenible como base de la conservación de la naturaleza.}

Aplicado al campo del turismo, el concepto de sostenibilidad se ha convertido en una forma de mediación que permite salvar las diferencias políticas e ideológicas que existen entre los grupos que defienden la ecología y los que propugnan el desarrollo, al tender puentes entre los paradigmas radicalmente opuestos del ecocentrismo y del antropocentrismo. Es un concepto que se sitúa a caballo entre el desarrollo y la conservación, que trata de conciliar ambos aspectos y 
lleva implícito el diseño y la aplicación de prácticas de desarrollo y explotación alternativas y controladas.

La sostenibilidad está ligada de forma inherente a la conservación, ya que se basa en la capacidad que tiene el medio ambiente para renovarse, impidiendo que esta capacidad se vea reducida o perjudicada. La conservación incluye ideas como proteger de los daños, el deterioro y las pérdidas, especialmente en lo que se refiere al uso futuro; la protección, la conservación y la gestión responsable de los recursos naturales y del medio ambiente. Supone por lo tanto una especie de "desarrollo moderado", en el sentido de que, como mínimo, el desarrollo ha de ser sostenible, en tanto en cuanto no ponga en peligro los sistemas naturales en los que se sustenta la vida en el planeta -la atmósfera, las aguas, los suelos y todos los seres humanos-. Tal es el sentido de la definición de "desarrollo sostenible" surgida por primera vez en el Informe Bruntland -el Informe de la Comisión Mundial de Medio ambiente y Desarrollo, 1987, conocido también por el título "Nuestro futuro común" (Oxford: Oxford University Press, 1987)- identificándolo como "el desarrollo que satisface las necesidades del presente sin comprometer la capacidad de las generaciones futuras de satisfacer sus propias necesidades". La sostenibilidad exige establecer datos de partida desde los cuales se pueda medir el cambio o el ritmo al que éste se produce (COMISIÓN MUNDIAL DE MEDIO AMBIENTE Y DESARROLLO, 1987; FUNDACIÓN MUNDIAL PARA LA NATURALEZA, 1992).

Así, el turismo sostenible desde el punto de vista medioambiental se ha venido identificando fundamentalmente con el turismo verde. BUTLER R. W (1991) define el turismo sostenible como "un tipo de turismo que favorece el equilibrio ecológico" y "sugiere una definición de partida del desarrollo sostenible en el campo del turismo en los siguientes términos: el turismo que se desarrolla y se mantiene en una zona (comunidad, entorno) de una manera y a una escala tales que esta actividad turística resulte viable durante un periodo indefinido y no deteriore o altere el medio ambiente".

Conseguir que se produzca un impacto mínimo implica que los viajes ecológicos se organicen a pequeña escala, por lo cual no se necesita mucha infraestructura especializada y no se contribuye a dañar el entorno del que depende el ecoturismo (y todas las modalidades turísticas). Porque, como Butler expresa de forma sucinta, "si el ecoturismo daña los recursos naturales, entonces deja de ser ecoturismo". En términos similares se expresa Bragg cuando afirma que "el ecoturismo, por definición, produce un impacto medioambiental mínimo, ya que los entornos de naturaleza virgen son la atracción de este tipo de turismo" (BRAGG, 1990). 
Tras muchos debates en conferencias internacionales -las principales se celebraron en 1992 (la Cumbre de La Tierra organizada por las Naciones Unidas; la reunión de la Unión Internacional para la Conservación de la Naturaleza y de los Recursos Naturales, y el IV Congreso Mundial sobre Parques Naturales y Zonas Protegidas) y más recientemente, en el año 2002 en correspondencia con la Declaración del Año Mundial del Ecoturismo (Declaración de Québec (Canada) y Cumbre Mundial del Desarrollo Sostenible (Johannesburgo)-, los conservacionistas y los operadores turísticos responsables están convencidos de que la conservación es parte esencial de cualquier definición de ecoturismo. Así pues, para que una actividad o experiencia se catalogue como "ecoturismo" debe aportar algo positivo al medio ambiente: si el medio ambiente no ha conseguido al menos un beneficio neto de cara a su sostenibilidad y a su integridad ecológica, entonces esa actividad no puede denominarse ecoturismo. Planteamiento éste más discutible en la práctica, pues a menudo se aplica el concepto de ecoturismo de forma inapropiada, especialmente en el caso de espacios naturales en los que son frecuentes problemas de saturación, frecuentación masiva,etc..., con la reproducción en ámbitos distintos de los inconvenientes apuntados sobre el turismo convencional.

\section{ECOTURISMO VERSUS VACACIONES DE NATURALEZA: EN BUSCA DE UNA DEFINICIÓN.}

La definición de Ecoturismo provoca discusión al tiempo que resulta difícil de perfilar con precisión. Con todo, algunas ideas pueden aclararse y extraerse a partir del análisis de las principales corrientes ideológicas que lo inspiran, y que han sido comentadas. En este sentido, y con independencia de las observaciones y de las matizaciones que puedan hacerse al respecto, parece bastante acertado decir que el ecoturismo es una forma de turismo alternativo al turismo de masas, con una particular orientación filosófica hacia la naturaleza y basado en la aplicación de estrategias para lograr un desarrollo sostenible.

El ecoturismo, por tanto, y desde un punto de vista teórico, se puede describir como un turismo mesurado, que produce un mínimo impacto en el entorno, e interpretativo, en el que se persiguen objetivos relacionados con la conservación, la comprensión y el aprecio por el entorno y las culturas que se visitan. Es un campo especializado del turismo que supone viajar a zonas vírgenes, o a territorios donde la presencia humana es escasa, en el que el ecoturista involucrado en la experiencia del ecoturismo expresa una motivación explícita en satisfacer la necesidad de educarse y concienciarse desde el punto de vista medioambiental, social y/o cultural mediante la visita y la experiencia vivida en la zona de naturaleza en estado puro de que se trate. 
Héctor Ceballos-Lascurain es la persona que primero acuñó el término "ecoturismo". En 1982, Ceballos-Lascurain empezó a usar la expresión "turismo ecológico" para designar las modalidades del turismo orientadas hacia la ecología. Esta expresión se acortó dando lugar al término "ecoturismo" en 1983. Ceballos-Lascurain identifica el ecoturismo como la forma de viajar en la que el entorno natural es el elemento central, siendo éste el que nos proporciona un punto de partida simple, pero también esencial, para entender el fenómeno del ecoturismo; especialmente si éste se considera una forma específica de turismo alternativo. El papel esencial que desempeña el entorno natural en el ecoturismo se manifiesta en dos facetas principales: el ecoturismo implica viajar a entornos naturales vírgenes o escasamente antropizados; el objetivo que prima en el viaje es interiorizar la experiencia que proporciona estar rodeado de entornos naturales de estas características (protegidos o no).

Desde esta perspectiva, el ecoturismo además incluye varios elementos fundamentales (NEIL, J.; WEARING, S. y OTROS, 1999: 31-33): en primer lugar, la noción de movimiento o viaje de un lugar a otro. Se supone que este viaje se restringe a zonas naturales relativamente inexploradas o protegidas, ya que el interés principal del ecoturismo se centra fundamentalmente en la experiencia de encontrarse rodeado de ambientes de naturaleza. Las zonas naturales protegidas o inexploradas ofrecen la mejor garantía de encontrar rasgos y atractivos naturales de forma sostenida.

Esto nos lleva a un segundo componente que debe aparecer en la definición de ecoturismo, concretamente que éste está íntimamente ligado a la naturaleza. El ecoturismo consiste en viajar a marcos naturales relativamente vírgenes, con fines de estudio, de disfrute (práctica de actividades deportivo-recreativas, culturales) o para intervenir en programas de ayuda voluntaria relacionada con la flora, la fauna, la geología y los ecosistemas de una región, así como con la gente (cuidadores) que vive en zonas próximas, sus necesidades, sus cultura y su relación con la tierra.

En tercer lugar, el ecoturismo está ligado hacia la conservación. Como segmento de la industria turística, el ecoturismo ha surgido como consecuencia de la creciente preocupación global por la desaparición de culturas y ecosistemas y como expresión del rechazo al desarrollo inadecuado del turismo que pueda deteriorar una zona protegida y producir efectos imprevistos desde el punto de vista económico, social y medioambiental en los territorios circundantes. El objetivo del ecoturismo es, pues, llevar a grupos pequeños de personas a marcos naturales o zonas protegidas produciendo un impacto mínimo en el entorno físico, social y cultural. A la noción de conservación se añade la idea de que el ecoturismo debe contribuir a garantizar un futuro sostenible para el destino en el que tiene lugar, ya sea en forma de beneficios económicos o de ayuda volunta- 
ria. De esta manera, el ecoturismo tiene potencial para impulsar la conservación de recursos naturales haciendo que la gente sea más consciente de la importancia de estos recursos naturales y, por esta razón, la noción de la conservación debe figurar en la definición de ecoturismo.

La cuarta idea que debe aparecer en la definición de ecoturismo es que tiene una función educativa. El ecoturista expresa generalmente un gran deseo de adquirir más conocimientos acerca de la naturaleza durante sus viajes. Por tanto, se hace mucho hincapié en apreciar, estudiar e interpretar la naturaleza mediante la explicación de los conceptos, el significado y las interrelaciones de los fenómenos naturales. La dependencia que el ecoturismo tiene respecto a la naturaleza, al contrario que otras formas de turismo en las que el papel de la naturaleza es secundario para la experiencia vacacional, incluye la motivación turística de satisfacer una necesidad educativa que se deriva de las interacciones con el entorno natural.

Esta función educativa se refiere no sólo a los propios turistas sino también a los operadores de la industria del turismo y a las comunidades locales. La necesidad de difundir información entre los turistas acerca de la conducta apropiada en entornos sociales y ecológicos frágiles se ve cada vez más como una responsabilidad que han de asumir los operadores de la industria. Gracias a su participación activa, los ecoturistas poseen la formación necesaria para apreciar la importancia de la conservación de la naturaleza y de la cultura. El ecoturismo atrae a personas que desean interactuar con el medio ambiente $y$, en diferentes grados, ampliar sus conocimientos sobre él, para comprenderlo y apreciarlo aún más. El ecoturismo puede también proporcionar a los miembros de las comunidades locales la oportunidad de aprender cosas sobre las zonas y los puntos atractivos que los turistas vienen a visitar, lo que permitirá que ellos disfruten igualmente de esos enclaves. Así pues, en lo que a la comunidad receptora se refiere, el ecoturismo puede estimular también que vuelvan a apreciar el valor único de sus propias tradiciones culturales a resultas del interés que los turistas muestran por ellas, tal y como muestra el Cuadro 1 donde se sintetizan los elementos esenciales del ecoturismo, y especialmente, los beneficios que supone para la dinamizar el medio socio-económico de los ámbitos receptores.

Bien planteado, en consecuencia, el ecoturismo es un instrumento que, ligado al concepto de viajes a zonas naturales con fines de aprovechamiento pero también de educación y de conservación, posee potencialidades enormes tanto para entender mejor los valores medioambientales, como para dinamizar la economía y la sociedad de los espacios receptores y garantizar una experiencia turística de calidad a los visitantes potenciales.Hablar de un ecoturismo bien planteado, significa ante todo, que los principios de gestión cuidadosa y planificación sostenible gocen de efectividad real en estos ámbitos. 


\section{ECOTURISMO VERSUS PRODUCTO TURÍSTICO: EL MERCA- DO DEL ECOTURISMO.}

La exposición y el comentario de los rasgos y peculiaridades del ecoturismo obliga a la consideración de su dimensión aplicada, en el sentido de analizar los elementos que componen la oferta y la demanda, esto es, el mercado del ecoturismo propiamente dicho. En definitiva, tratar de entender los mecanismos a través de los que se lleva a la práctica y se justifica la dinámica de funcionamiento de esta actividad.

El Ecoturismo, como variedad específica del turismo, es ante todo, una actividad económica, y especialmente un producto turístico. Como tal, debe tener estructurado perfectamente su propio mercado, teniendo presente que sólo se producirá un auténtico desarrollo del ecoturismo cuando se produzca una adecuación verdadera entre los intereses, las expectativas y los deseos de la demanda (clientela) y las características de la oferta.

\section{Análisis de la oferta: la necesidad de un modelo integrado de oferta.}

Una planificación adecuada del Ecoturismo supone conocer y clasificar los distintos elementos de su oferta. En este sentido, hay que subrayar que la base del Ecoturismo está compuesta por tres categorías de elementos: de un lado, los recursos territoriales turísticos; de otro, la oferta de servicios e infraestructuras; y finalmente el modo de gestión y comercialización. Nos detenemos en el comentario de los dos primeros, básicamente por razones de espacio y de coherencia en relación con los objetivos de nuestro artículo.

Entendemos por recursos turísticos aquellos atractivos que están en el espacio natural-rural y que pueden atraer la atención de visitantes y turistas, convirtiéndose en el motivo del desplazamiento y la estancia en una comunidad o entorno determinado. Aunque su conocimiento pueda parecer sencillo a priori, no lo es, y la variedad y tipología de recursos territoriales turísticos obliga a un esfuerzo de clasificación que facilite su correcta ubicación a la hora de difundirlo, aprovecharlo y conservarlo.

Desde esta perspectiva, todo espacio susceptible de ser ofertado como producto turístico, en este caso, como producto ecoturístico, debe contar con un inventario de recursos territoriales, cuya realización requiere de un exhaustivo trabajo de campo en el que se inventaríen los recursos turísticos básicos, divididos básicamente en, por un lado, los recursos naturales (ríos; piscinas naturales; caídas de aguas; aguas termales; cuevas; masas arbóreas; balcones paisajísticos; fauna; flora; comunicaciones -pistas forestales, senderos, antiguas vías pecuarias, cañadas reales, calzadas romanas); por otro, los recursos histórico-artísticos (arquitectura local; arqueología; museos, monumentos; documentación histórica); 
otro conjunto de recursos atiende aquellos aspectos de índole cultural y antropológicos (fiestas locales; artesanía; gastronomía; leyendas; instrumentos musicales tradicionales; utillaje agrícola, doméstico o ganadero;documentación gráfica (fotos, grabados); juegos y deportes autóctonos;y finalmente, un último tipo de recursos tiene que ver con todo lo relacionado con equipamientos, infraestructuras y servicios (DEL REGUERO, M.,1994,89-92).

Conviene profundizar en el tema de los equipamientos y de las infraestructuras y servicios turísticos, pues resulta evidente que los recursos turísticos por sí solos no satisfacen las necesidades del turista si no se le facilitan unos servicios $\mathrm{y}$ unas infraestructuras que permitan acceder y disfrutar de sus posibilidades.

Desde esta óptica, para afrontar el análisis de la oferta del Ecoturismo, y dejando a un lado los recursos turísticos naturales, histórico-artísticos y culturales, puede hacerse así mismo una división de los equipamientos y servicios en dos categorías básicas: la oferta básica de servicios y la oferta complementaria.

La oferta básica de servicios está constituida por aquellos que le permiten acceder y permanecer al turista en el lugar de destino. Para acceder se necesita un medio y unas infraestructuras de transporte, y para permanecer un alojamiento y servicios de manutención.

El medio de transporte más utilizado por los ecoturistas es el vehículo propio, seguido del autobús y del tren. Para el desarrollo del ecoturismo son de vital importancia así mismo las infraestructuras de transporte con las que cuenta la zona. De su existencia o no y del estado o calidad de las mismas va a depender en buena medida el éxito de nuestra oferta turística.

El alojamiento es igualmente un servicio básico en cualquier oferta turística. Además, cuando está ubicado en un inmueble típico o de valor artístico, lo cual es bastante frecuente en entornos de carácter natural y rural, puede convertirse en un recurso turístico en sí mismo. Algunos de los alojamientos más característicos del medio rural son los siguientes: Hostelería rural de calidad (Paradores, Posadas, etc..); Alquiler de casas rurales; Alquiler de habitaciones dentro de la vivienda familiar; Alojamiento en granjas y caseríos; Camping-rural; Ciudades de vacaciones (albergues, refugios,etc...).

Finalmente, la manutención es un servicio básico para el turista que en el turismo rural puede convertirse también en un recurso o atractivo turístico, tal como ocurre en múltiples destinos turísticos en el medio rural. El disfrute de la gastronomía de la zona y el consumo de productos naturales y autóctonos es una de las principales motivaciones del turista rural. 
La oferta de servicios complementarios está integrada por aquellos elementos que permiten disfrutar de nuestra estancia en el medio rural, de sus atractivos y de sus recursos y está compuesta, en primer lugar, por los servicios no turísticos que el turista demanda en su destino. De carácter variado, son aquellos que sirven de soporte a la actividad turística, pudiendo agruparse del siguiente modo: infraestructura viaria y de comunicaciones (redes arteriales de carreteras, aeropuertos, puertos comerciales, puertos deportivos, líneas de ferrocarril, nudos principales de carreteras, etc..); infraestructura energética: energía eléctrica (potencia, posibilidades y distancia de enganche), distribuidores de butano y otros productos similares relacionados con el abastecimiento energético); infraestructura de abastecimiento de agua (redes municipales, depósitos, fuentes, etc...); equipamiento comercial (supermercados, tiendas de alimentación, tiendas de ropa, de menaje, ferretería, talleres de automóviles, etc..); equipamiento administrativo y de servicios: Ayuntamiento, Cuartel de la Guardia Civil, Oficina de Correos y Telégrafos, Teléfono Público, etc..); equipamiento sanitario (Hospital, Centros de Salud, Puesto de la Cruz Roja, Farmacia, Asistencia Médica las 24 horas); equipamiento financiero (Bancos, Cajas de Ahorro, etc..).

En segundo lugar, y en el marco de la oferta complementaria, hay que señalar los servicios propiamente turísticos, que comprenden las diferentes actividades turísticas que pueden realizarse en el espacio rural y que permiten disfrutar de los recursos: En este sentido, podemos realizar aquí también una clasificación doble, realizando un comentario de, por un lado, las actividades de carácter recreativo-deportivo y, por otro, las de animación socio-cultural.

\section{a) Actividades de carácter recreativo-deportivo}

La oferta de estas actividades nace del perfil humano de la actual clientela del turismo en espacios naturales y rurales, esto es, del ecoturista (V. Epígrafe 2). Como se verá, en líneas generales los ecoturistas son personas de un nivel medio-alto cultural y que no gustan de un turismo pasivo, sino todo lo contrario. Suelen estar preocupados, dado su carácter normalmente urbano, por la salud física y por una vida natural y sana en contacto con la naturaleza y haciendo ejercicio.

La lista de actividades puede ser inacabable, hasta el punto de que cada vez hay más editoriales que sacan a la luz guías de turismo activo en las que se recogen, de forma pormenorizada todas estas actividades, su definición y la relación de establecimientos que los ofertan, indicando su localización y precios, tanto por provincias como por Comunidades Autónomas (para el caso de España en concreto). 
Las más comunes pueden dividirse en tres categorías principales, atendiendo a los recursos o elementos del medio natural que sirven de soporte para su realización:

1. Elemento Agua: Baño; Remo; Piragüismo; Rafting; Descenso de cañones; Paseos náuticos en río; Pesca; Cruceros fluviales; Windsurf; Velomar; Vela; Surfing; Submarinismo; Cruceros de litoral; etc...

2. Elemento Tierra: Senderismo; Trekking; Trineos; Equitación; Escalada; Esquí Nórdico; Esquí Alpino; Snowboard; Cicloturismo; Bicicleta de Montaña (BTT); Espeleología,etc..

3. Elemento Aire: Ala delta; Parapente; Aeroestación; Vuelo sin motor, etc..

\section{b) Actividades socio-culturales}

Si en las actividades deportivas dominan las tendencias lúdicas y deportivas del acto turístico, en las actividades socio-culturales dominan las tendencias interpretativas-educativas, de descubrimiento del medio rural tanto en su naturaleza, tanto en su cultura humana. Esta faceta explica la importancia del turismo infantil y juvenil educativo en el medio rural-natural, cuya máxima expresión puede ser la de la "Semana Verde" francesa por la que los escolares franceses asisten, durante una semana, a clases en un espacio rural francés para el estudio de su flora, su fauna y su cultura humana. Ello ha llevado a la creación de equipamientos específicos, entre los que destacan las granjas-escuelas, las aulas de la naturaleza, los ecomuseos o los centros de interpretación, como los más representativos y que actualmente ya se extienden por todo el espacio europeo.

Pero no sólo los escolares son personas interesadas en estos equipamientos, sino que también los adultos pueden tener interés en ellos, complementándose en el tiempo: los escolares usan el equipamiento de lunes a viernes y los adultos en fin de semana. Las actividades a proponer son muy diversas: Visita a artesanos y cursos de artesanía; Rutas sobre patrimonio artístico y arquitectónico rural; Promoción de la gastronomía local; Recorridos ecológicos en distintos medios de transporte; Rutas etnológicas; Espectáculos culturales; Seminarios, Coloquios, Jornadas, Encuentros; Rutas fotográficas de iniciación a la fotografía de la naturaleza, etc...

Entre las necesidades ineludibles para que se produzca una materialización y un desarrollo efectivo del turismo en los espacios naturales destacan: de un lado, la búsqueda del consenso y de la adhesión de la población local o rural a un modelo de desarrollo endógeno; en segundo lugar, la necesidad de una gestión, promoción y comercialización integrada de los productos turísticos en los espa- 
cios naturales y rurales; y finalmente, la acción sinérgica (en común) de las distintas administraciones responsables. Todo ello sin olvidar las peculiaridades inherentes a ese nuevo tipo de turistas en teoría más responsables y con inquietudes y motivaciones diferentes, a los que se ha venido a llamar, desde la perspectiva de la demanda, "ecoturistas".

\section{El perfil del ecoturista: análisis de la demanda.}

Con el auge del turismo alternativo, ha surgido un nuevo colectivo de turistas que exigen que la industria enfoque el turismo de una forma distinta, introduciendo actividades y experiencias diferentes. De este modo han surgido los ecoturistas. Básicamente podrían definirse como gente inquieta, activa, que necesita explotar posibilidades de ocio que sean compatibles con el medio ambiente, actividades donde prevalezca la naturaleza por encima de los intereses de la especie humana. Estos ecoturistas están rompiendo las ataduras del turismo convencional o de masas para buscar nuevos conocimientos y experiencias. Sus intereses no se centran en estar repantigado sin hacer nada junto a la piscina de un hotel o en seguir ajetreados programas de visitas turísticas. Por el contrario, sí están interesados en visitar zonas silvestres, espacios naturales protegidos, disfrutar en entornos rurales, hacer deporte en la naturaleza, observar la flora y la fauna, etc... en definitiva quieren experimentar nuevos estilos de vida y conocer a otras personas que tienen inquietudes similares a las suyas y, al mismo tiempo, quieren ver cómo el dinero que gastan en sus viajes se convierte en una aportación a las tareas de conservación y se traducen en beneficios para la economía local.

Se trata aquí de definir lo más acertadamente el perfil característico de un ecoturista potencial, sobre la base del comentario de sus peculiaridades demográficas, psicográficas, de sus necesidades, de sus actitudes y de sus expectativas ante un destino determinado; unas peculiaridades que le otorgan un sesgo claramente diferenciador en relación con el turista convencional. El conocimiento de estos aspectos resulta de gran interés, no sólo en una perspectiva teórica, sino por lo que significa en relación con sus implicaciones empresariales en cuanto a los operadores de ecoturismo, agencias, etc... y su necesidad de armonizar el producto ofertado a las características, expectativas y exigencias de los consumidores potenciales.

Desde este último punto de vista, lo primero a destacar es la existencia de dos grupos principales de características que permiten descubrir los rasgos distintivos de los ecoturistas. De un lado, las características demográficas, y de otro, las psicográficas. La segmentación demográfica implica definir el mercado del ecoturismo en función de variables tales como la edad, el sexo, la fase del ciclo vital, el trabajo, el nivel de ingresos y el nivel cultural. Es pues, un método de 
análisis cuantitativo, en tanto que el perfil psicográfico presenta un carácter cualitativo y analiza datos menos tangibles como los valores y las motivaciones de los ecoturistas.

Desde el punto de vista demográfico, los ecoturistas se caracterizan, en términos generales, por tener ingresos que superan la media, en la mayoría de los casos titulación superior y están distribuidos de forma equitativa entre los dos sexos. Un estudio realizado en 1992 por el Centro de Datos y Viajes de Estados Unidos demostró que existía un 5\% más de probabilidades de que los ecoturistas tuvieran ingresos por encima de los 40.000 dólares y un 13\% más de que tuvieran títulos universitarios que entre la población en su conjunto. WIGHT (1996) va más allá y diferencia dos grupos dentro del colectivo de ecoturistas, destacando los consumidores normales que sienten curiosidad por el ecoturismo y los viajeros ecoturistas experimentados. Los ecoturistas con experiencia que fueron entrevistados por Wight poseían un nivel cultural alto, superior al de los turistas normales que sentían curiosidad por el ecoturismo y tendían a viajar en pareja (61\%), con una familia no muy grande (15\%) o sólos (13\%), en comparación con los turistas normales que viajaban mayoritariamente en pareja (59\%) y en familia 26\%). La diferencia más llamativa aparecía en el gasto -los ecoturistas experimentados estaban dispuesto a gastar más que los turistas normales-, es decir, que el ecoturista experimentado es proclive a gastar más que el turista convencional. Otro estudio llevado a cabo en 1990 por encargo del Fondo Mundial de Protección de la Flora y la Fauna Silvestres reveló que las personas interesadas en los viajes de naturaleza y en las visitas a entornos naturales frágiles muestran normalmente niveles de gasto más altos que el turista medio, gastando de media un $8,5 \%$ más en los servicios y productos que les ofrecen proveedores ecológicamente responsables ${ }^{8}$.

\footnotetext{
${ }^{8}$ Recientemente, un proyecto de investigación encargado por la Consejería de Cultura y Turismo a la Universidad de Valladolid sobre la práctica del turismo activo-deportivo en determinados espacios naturales protegidos de la región (en concreto los parques naturales de Picos de Europa (León), Sierra de Gredos (Avila), Cañón del Río Lobos (Soria), Hoces del Duratón (Segovia) y Lago de Sanabria (Zamora) destaca resultados muy parecidos en cuanto al perfil y las características de este tipo de turista, a partir de los resultados aportados por el muestreo realizado. Así, se pone de manifiesto aspectos como que la edad media de los visitantes a estos espacios no supera los 33 años, repartida equitativamente entre los dos sexos, la inmensa mayoría población es población ocupada (tan sólo un $17 \%$ afirma ser desempleados, con frecuencia identificados con población estudiante) y con un predominio del sector servicios (53\%). En cuanto al nivel de instrucción más de la mitad $(56,6 \%)$ han finalizado una carrera universitaria que se reparten entre el $21,2 \%$ con estudios medios y el resto, $35 \%$ con estudios superiores. Un $92 \%$ afirma ir en vehículo propio, la mayoría por libre (en ausencia de organización alguna) y justifica su visita por el fenómeno del "boca a boca"como medio de comunicación. Para más información sobre este tema véase. SALVADOR INSÚA, J.A. (Coord.): La práctica del turismo activo- deportivo en los parques
} 
En cuanto al país de origen, la mayoría de los ecoturistas proceden de naciones occidentales relativamente ricas como EEUU, Alemania, Suecia, Canadá y Australia y se trata de población de media edad -nacida entre 1946 y 1964-, siendo este estrato poblacional la tendencia demográfica fundamental en lo que al ocio y al turismo se refiere, tanto por la disponibilidad de tiempo de ocio como por el nivel de ingresos que pueden dedicar en servicios relacionados con él.

Junto a estas características socioeconómicas (demográficas), aparecen toda una serie de pautas de actitud y de conducta (características psicográficas) que nos proporcionan datos significativos a la hora de distinguir a los ecoturistas. En términos generales, desde este punto de vista puede afirmarse que los ecoturistas: se rigen por una ética medioambiental; muestran disposición a no deteriorar los recursos; prestan más atención a la motivación intrínseca que a la extrínseca; muestran una orientación biocéntrica y no antropocéntrica; tienen como meta lograr beneficios para la flora y la fauna silvestres así como para el medio ambiente; se esfuerzan por tener una experiencia o contacto de primera mano con el entorno natural; poseen expectativas en lo que a adquisición de conocimientos y aprecio del valor de los recursos se refiere y se da un fuerte protagonismo de los aspectos cognitivos y afectivos.

Los ecoturistas muestran una preferencia por los grupos reducidos y el servicio personalizado, tienden a ser entusiastas de las actividades al aire libre y viajan a menudo en pareja o individualmente, siendo además viajeros habituales y, por tanto, experimentados. Suelen aceptar con más facilidad que otros tipos de turistas encontrarse en condiciones distintas a las de su hogar. El alojamiento lujoso, la comida y la vida nocturna son mucho menos importantes para este grupo que la posibilidad de vivir en las mismas condiciones que las comunidades locales y disfrutar de las costumbres y la comida de los lugareños. Debido a su "clara orientación científica" y al hincapié en el estudio y el aprendizaje, los ecoturistas, al contrario que otros tipos de turistas, están deseosos de obtener instrucción acerca de los destinos que visitan.

Están interesados en la naturaleza por derecho propio, también disfrutan del desarrollo personal que permite la realización de actividades físicas, la experiencia de familiarizarse con estilos de vida nuevos y más simples, conocer a gente con inquietudes similares, asistir a manifestaciones culturales y comprar objetos de artesanía local.

En este sentido, el ecoturismo es algo más que una mera actividad de ocio. Es un estilo de viajar que refleja y fomenta una orientación concreta no sólo hacia

naturales de Castilla y León: una posibilidad de desarrollo socio-económico para el mundo rural. Inédito. Consejería de Cultura y Turismo. Junta de Castilla y León. 2003. 
los viajes, sino también hacia unas formas de vida, unas conductas y unos planteamientos filosóficos muy significativos: "Los ecoturistas esperan realizar descubrimientos y adquirir conocimientos relacionados con su experiencia de ecoturismo. La maduración personal en términos tanto emocionales y espirituales como intelectuales parece ser un resultado esperado de los viajes de ecoturismo para la vida de estos viajeros" (WILLIAMS, 1990).

\section{a) Las motivaciones turísticas.}

Dado que la gente actúa para satisfacer sus necesidades, se cree que la motivación es la fuerza motriz que en último término impulsa y dicta la conducta relacionada con los viajes. Por tanto, la motivación de los turistas debería constituir la base de las estrategias de marketing turístico. La investigación acerca de la motivación parte de los primeros trabajos de DANN G. (1981) en los que se explicaba que los factores de "empuje" y de "arrastre" resultan fundamentales a la hora de motivar a los turistas. Los factores de empuje surgen en el interior del individuo, mientras que los motivos de arrastre los provoca el destino turístico. Los factores de empuje establecen el deseo de viajar y los factores de arrastre explican la elección de un destino concreto.

Los factores de empuje están estrechamente relacionados con la jerarquía de necesidades establecida por Maslow: Según este autor, la actualización es la principal fuerza impulsora de la personalidad humana, pero antes de dedicarse a esta actualización, hay que satisfacer necesidades relacionadas con motivaciones más básicas como el hambre, el refugio y la seguridad. Maslow distribuyó estas necesidades en cinco niveles: Fisiológicas (hambre, sed, refugio,sexo,etc..); De seguridad (protección frente a los daños físicos y emocionales); Sociales (cariño, pertenencia a un grupo, aceptación, amistad,etc..); De estima (tanto interna, respecto a uno mismo, autonomía, logro) como externa (estatus, reconocimiento, atención); y finalmente, necesidades de autorrealización.

Un esquema de motivación turística elaborado por PEARCE (1993 y1998) y basado en la jerarquía de necesidades de Maslow proporciona un marco expansivo que sirve para identificar las necesidades que un turista está intentando satisfacer cuando viaja. Un turista convencional está más preocupado por la satisfacción de necesidades de un nivel más bajo como las que tienen que ver con la relación, el estímulo y la relajación, mientras que los ecoturistas están más preocupados con el desarrollo y la realización personal, en la que se incluye la autoeducación. Si el centro de atención del ecoturismo son las actividades centradas en la naturaleza, es lógico pensar que los ecoturistas, por el tipo de experiencia que buscan, prestan más atención a la autorrealización y a las necesidades de un rango más elevado que a las necesidades básicas situadas en la parte baja de la jerarquía. Como hacen notar Mayo y Jarvis, las necesidades intelec- 
tuales pueden en algunas ocasiones tener prioridad sobre algunas de las necesidades de rango más bajo. Por ejemplo, la curiosidad, la exploración, la aventura, el deseo de aprender y de comprender son necesidades que se intentan satisfacer incluso aunque esto suponga un alto coste para la seguridad del individuo (MAYO y JARVIS (1981).

Eagles también comprobó que las motivaciones de un ecoturista y las de un turista convencional difieren en relación con el contraste de motivaciones intrínsecas y extrínsecas para viajar. Este autor descubrió que al turista convencional en la mayoría de los casos le gustaba sentirse como en casa cuando se encuentra fuera de casa (EAGLES, 1994).

La elaboración de productos hechos a medida sirviéndose de la investigación realizada en torno a las motivaciones es importante en cualquier sector del turismo. Reconocer que los motivos de los ecoturistas son diferentes resulta esencial para los gestores turísticos. Adaptarse a las necesidades de este segmento de mercado resulta fundamental. La capacidad que tienen los operadores de ecoturismo de satisfacer las necesidades de los ecoturistas será determinante para saber si el enclave turístico en cuestión se considera o no en último término un destino de ecoturismo viable y que merece la pena.

Desde la perspectiva de las actitudes y las conductas de los ecoturistas en relación con el entorno social y ecológico que les rodea, puede afirmarse que, en general, la tendencia más probable es que busquen la inmersión y la incorporación activa al entorno local, y en absoluto que intenten forzar la creación de un barrera artificial entre ellos y la comunidad que los acoge. COHEN (1972) define esta última tendencia con el término "burbuja medioambiental" mediante la cual el turista se separa del entorno que lo rodea en el destino turístico, por ejemplo, las instalaciones de centros turísticos, donde las posibilidades de dedicarse a actividades de ocio se circunscriben en gran medida al interior del complejo turístico. Los ecologistas tienden a buscar un conocimiento íntimo del medio ambiente, algo que no constituye un factor esencial para los turistas convencionales, que ponen más barreras.

La actitud del turista influye de manera significativa en su conducta con respecto al medio ambiente. Se admite abiertamente por parte de la mayoría que los turistas convencionales que tienden a tener una actitud más indiferente con respecto a las cuestiones ecológicas durante sus vacaciones.

La diferencia en cuanto a conducta entre el ecoturista y el turista convencional se relaciona directamente con el hecho de que la actitud y la motivación que impulsan a viajar a uno y otro grupo son muy distintas. Los ecoturistas viajan para experimentar la sensación de encontrarse en entornos naturales, para 
aprender cosas acerca de estas zonas, buscan conocer lo auténtico, lo genuino. Los turistas convencionales, por su parte, viajan para satisfacer necesidades relacionadas con el ocio, el placer y las actividades recreativas en general. Así pues, cuando se trabaja con el segmento de mercado de los ecoturistas, los operadores -tanto los gestores como los que se dedican a la comercialización- al igual que los administradores de zonas naturales protegidas y las comunidades locales, deben tener muy en cuenta aspectos como las diferentes percepciones, las necesidades y las actitudes de los clientes, así como los niveles de administración medioambiental responsable y los impactos probables que se puedan producir.

\section{ECOTURISMO Y ZONAS PROTEGIDAS: EN BUSCA DE LA SOSTENIBILIDAD.}

Tal y como se ha comentado, el ecoturismo y el turismo orientado hacia la naturaleza se realiza a menudo en zonas protegidas, zonas de excepcional belleza, de interés ecológico y gran importancia cultural. Hoy día, estas zonas se han establecido, al menos en la teoría, para conservar la biodiversidad y para detener la pérdida de ecosistemas a gran escala.

Es por esto que, precisamente en los espacios naturales protegidos, es donde resultan más evidentes las opiniones encontradas acerca del valor intrínseco y utilitario de la naturaleza, es decir, donde se aprecia de forma más clara el conflicto entre las dos orientaciones fundamentales desde el punto de vista de la función y de la finalidad, "conservación" frente a "uso". En este sentido, el turismo en zonas protegidas representa precisamente la plasmación de ese dilema, pues al fin y al cabo el turismo es, en esencia, una actividad de recreo, en la que el valor que se le da a la naturaleza tiene que ver con las dimensiones de "catedral" y de "gimnasio" que argumentaba Godfrey-Smith. Las zonas protegidas son aparentemente incompatibles con ese tipo de actividades, al tener como función primordial la conservación de los ecosistemas naturales. La notoriedad que presenta hoy en día esa discusión acerca del turismo en los parques naturales no es sino la extensión de una prolongada controversia que existe ya desde el mismo momento en que surgió esta concepción de zonas protegidas y reservas equivalentes.

Históricamente, los parques se crearon en un principio con fines utilitarios, pero ya desde la creación de los primeros parques se ha ido produciendo una importante reorientación por la cual se ha pasado del énfasis en las actividades turísticas y de ocio que predominaba en un principio a un marcado interés por los objetivos relacionados con la conservación. 
En el pasado, el ocio y el turismo apenas representaban una amenaza para los parques, debido a factores como la distancia y el difícil acceso a los mismos, así como al volumen no muy elevado de visitantes. Sin embargo, se ha producido un cambio significativo a este respecto en los últimos quince o veinte años, a medida que las zonas protegidas han ido cobrando cada vez más relevancia, tanto por la mayor movilidad de la población y la mayor disponibilidad de tiempo libre como por el hecho de que los colectivos humanos son cada vez más conscientes de la importancia del medio ambiente, un cambio que se ha traducido, por un lado, en el número de visitantes en los parques - y en el impacto que se deriva de esa mayor presencia humana- y por otro, en el papel esencial que estas zonas van a desempeñar en las tareas de conservación.

La aceptación de volúmenes mayores de visitantes, como precio que se ha de pagar para poder afrontar el mantenimiento, pone en serio peligro las cualidades naturales excepcionales que sirven de base para el establecimiento de un espacio natural protegido. Como se ha comentado con anterioridad, día tras día se comprueban las presiones cada vez mayores a las que se ven sometidos los recursos naturales, que hacen cada vez más patente la necesidad de proteger los recursos, especialmente los que se encuentran en zonas protegidas y en reservas equivalentes.

Aunque la concepción de las zonas protegidas no es idéntica en todos los países del mundo, la Unión Internacional para la Conservación de la Naturaleza identifica las características que son comunes a todas ellas. En esta definición se identifican claramente los valores de conservación como objetivo fundamental. En ellos se incluye la protección de la diversidad genética y biológica, y la provisión de las condiciones necesarias para realizar controles biológicos que sirvan de referencia a la hora de contrastar los efectos que se asocian con el desarrollo. Sin embargo, también se reconoce el derecho legítimo al acceso por parte del público "en condiciones especiales" (con fines relacionados con el ocio, por ejemplo) (UNIÓN INTERNACIONAL EN PRO DE LA CONSERVACIÓN DE LA NATURALEZA, 1985).

El ecoturismo, en tanto que estrategia para lograr el desarrollo sostenible, constituye cada vez más parte de una filosofía política a la que recurren los gestores de zonas protegidas y las agencias para la conservación, que encuentran en él un medio de obtener resultados prácticos en la lucha por sentar las bases que permitan conseguir la protección permanente para esta zonas. Entre estos resultados deben figurar, en primer lugar, una fuente de financiación para los parques y la conservación y, por tanto, obtener una justificación (económica) para la protección de los parques; de otro lado, una forma alternativa de desarrollo económico; $\mathrm{y}$, finalmente, la mayor difusión de los relacionados con la conservación entre el gran público. 


\section{Técnicas de gestión sostenible.}

Mientras que otros tipos de turismo más convencionales han modificado el entorno para adecuarse a las necesidades específicas de su clientela, los ecoturistas "en sentido estricto" no esperan y ni siquiera desean que se produzcan modificaciones sustanciales del entorno natural. En lugar de medir la calidad del recorrido turístico mediante estándares convencionales como la previsibilidad y la uniformidad de la experiencia vacacional, el éxito del ecoturismo se basa en lo inesperado. Al menos desde un punto de vista conceptual, el ecoturismo le proporciona al turista oportunidades para descubrir, participar activamente e interactuar con el medio ambiente que lo rodea, animándolo a que asuma un papel proactivo en la creación de su propia experiencia turística.

No obstante, y como se ha remarcado a lo largo de estas páginas, existe la inquietud de que el ecoturismo actúa de una forma muy parecida a la del turismo de masas, con la única diferencia de que en el primero se destruyen los recursos a un ritmo más lento (efectos acumulativos). Esta cuestión es fundamental en el sentido de que es importante que los gestores sean conscientes de los potenciales efectos adversos para poder combatirlos mediante la planificación cuidadosa y la gestión efectiva. Las agencias que administran las zonas protegidas pueden sentirse atraídas de forma significativa por los beneficios económicos del turismo, una circunstancia que puede poner en peligro los objetivos de conservación. Los gestores deben tener claros tanto los objetivos del parque como las importantes diferencias entre los distintos tipos de turismo y los impactos que produce en cada uno de ellos. Entre las cuestiones que se suelen asociar con el turismo en los entornos naturales vírgenes figuran el número excesivo de visitantes, el conflicto que se plantea entre los diferentes tipos de usuarios, los desperdicios, las tarifas que han de pagar los usuarios y la distribución de la información.

Así pues, un aspecto que se ha de tener muy en cuenta a la hora de afrontar las cuestiones relacionadas con la gestión del ecoturismo es la manera de buscar un equilibrio que consiga maximizar el disfrute por parte de los visitantes, pero minimice al mismo tiempo los efectos negativos que provoca el desarrollo turístico.

Es esencial resaltar que, incluso cuando el despliegue del ecoturismo tiene como objetivo proporcionar beneficios económicos a las zonas protegidas, el propio parque se debe administrar, observar y controlar de forma rigurosa, mediante la aplicación de medidas de protección que impidan el deterioro del enclave debido a la presencia de los turistas. Pero hay que ser conscientes de que la defensa de las zonas protegidas exclusivamente por su valor intrínseco resulta difícil. 
La meta del ecoturismo es, pues, una sostenibilidad con la que se intenta proporcionar una base de recursos para el futuro, y con la que persigue asegurar la productividad de la base de recursos, mantener la biodiversidad y evitar que se produzcan cambios ecológicos irreversibles, al tiempo que se garantizan la igualdad de oportunidades, tanto en el marco de un generación como entre generaciones sucesivas.

El ecoturismo quiere sacar provecho del aumento del turismo que se dirige a zonas protegidas famosas por su belleza sobresaliente y su extraordinario interés ecológico, con la intención de hacer que los beneficios derivados de esta actividad turística reviertan en la comunidad receptora. Se parte de la premisa de que el turismo sólo puede ser sostenible si se conservan y mejoran los activos naturales y culturales en los que se basa. Esto supone reducir el impacto social y biofísico que causa la presencia de visitantes, aumentar la concienciación y las iniciativas relacionadas con el medio ambiente entre los turistas, y por último ofrecer oportunidades para las personas cuya subsistencia, de no existir esas oportunidades, depende de la extracción de los recursos de la zona en cuestión.

Las directrices de gestión de entornos naturales atractivos resultan a menudo previsibles para los turistas que se inclinan por la naturaleza como destino de sus vacaciones. El control de la gestión sirve para proteger y conservar la zona, asegurándose de que se cumplan las expectativas del visitante, con lo que se garantiza el mantenimiento de una clientela junto con las bases de recursos naturales. Entre los factores que deben estar bajo control de los administradores y que pueden afectar tanto a esos entornos naturales atractivos como a las expectativas de los turistas, podemos citar la infraestructura y el desarrollo turísticos, los niveles de llegada de visitantes, los guías, el vandalismo, la compra de recuerdos, el acceso a las distintas zonas, alimentar a los animales,etc...básicamente.

En condiciones ideales, los grupos de ecoturismo deberían ser pequeños en volumen con el fin de proporcionar al cliente una experiencia de mayor calidad, ya que esto ayuda a reducir al mínimo las presiones y los impactos ecológicos, al tiempo que permite que se hagan realidad metas intrínsecas del turista. El ecoturismo puede fomentar que se aprecien los entornos naturales y las culturas tradicionales, al ofrecer al turista la posibilidad de experimentar de primera mano lo que se siente en uno de estos enclaves. Sólo cuando se da este contacto de primera mano con el entorno natural, en combinación con el interés por aprender y por buscar otras formas intrínsecas de disfrutar, se puede hablar de una verdadera "experiencia ecoturista".

La Capacidad de Carga de un espacio, el Espectro de Oportunidades para las Actividades de Ocio (EOAO), los Límites del Cambio Aceptable (LCA), la Gestión del Impacto producido por la llegada de Visitantes (GIV) y el proceso 
de Gestión de las Actividades de los Visitantes son algunos de los marcos propicios para la toma de decisiones orientadas hacia la sostenibilidad en el contexto de la administración en zonas protegidas. Cuando se ponen en práctica, ayudan a proteger el patrimonio natural y cultural de un país, hacen que el público valore más los recursos e intentan resolver el conflicto que plantea la relación entre recursos y usuarios (para más información véase NEIL J. y WEARING (1999).Todos ellos son instrumentos muy eficaces para evaluar y efectuar una proyección sobre los límites sostenibles y deseables del impacto que causan los seres humanos sobre los ecosistemas naturales. Una vez que se han establecido, estos límites deben ser objeto de un estricto seguimiento que permita garantizar el mantenimiento de unos umbrales de sostenibilidad mínimos que sirvan de referencia.

También existen toda una serie de técnicas que permiten gestionar el uso que realizan los visitantes. Destacan entre ellas, las restricciones de usos y la zonación de espacios, la creación de un sistema de senderos, el cobro de entradas y otras tarifas para usuarios, y de manera especialmente relevante desde nuestra perspectiva, el énfasis en la educación (NEIL, J. y WEARING, 1999) 9 .

Hemos reflexionado sobre el ecoturismo, su origen, sus fundamentos explicativos, buscando una definición lo más precisa posible, e insistiendo en las principales características de su estructura de mercado y en algunas de las técnicas para su gestión. El ecoturismo, en tanto que alternativa al turismo convencional y estrategia de desarrollo "sostenible", es un instrumento que, cuidadosamente planificado y gestionado de manera óptima, aplicando los controles adecuados, puede contribuir significativamente a dinamizar el desarrollo de ciertas zonas, al tiempo que favorece su conservación, y permite a los turistas disfrutar de una experiencia turística de calidad. Ahora bien, en un contexto crecientemente dominado por el neoliberalismo y el racionalismo económico, y pese al sesgo reaccionario que suponen los valores y la filosofía del ecoturismo (ecocentrismo), la realidad pone de manifiesto la dificultad de lograr que teoría y práctica coincidan. Compatibilizar en la práctica conservación y rentabilidad turística es una tarea posible pero dificultosa. Lograr el justo término entre utilización turística

\footnotetext{
${ }^{9}$ Ambos autores, además de profundizar en las diferentes técnicas de gestión y planificación de los espacios naturales protegidos, realizan asimismo un análisis e interpretación de las prácticas de gestión de espacios protegidos en el panorama internacional. En concreto, destaca el apartado en el que se valoran las actuaciones desarrolladas en Australia, al recoger la ponencia de P.Figgis (Miembro de la Orden de Australia y Vicepresidenta de la Fundación Australiana para la Conservación) sobre "Temas relacionados con la política de las zonas protegidas en Australia", así como el análisis sobre las estrategias llevada al respecto en Costa Rica, en concreto, en la Reserva Ecoturista de Selva Tropical Santa Elena y la Reserva Monteverde de Selva Costera Húmeda pp. 163-193.
} 
de los recursos y su conservación y mantenimiento es la clave, y resulta fundamental si lo que se pretende es ofertar realmente un producto distinto al turismo convencional. Para ello hace falta, como en todo, buenas dosis de sensibilidad, buen método (planificación racional), voluntad y consenso. Y en este sentido, la educación y la formación son cuestiones absolutamente indispensables.

\section{BIBLIOGRAFÍA}

ACUÑA, A. (1991): Manual didáctico de actividades en la naturaleza, Sevilla, Wanceulen.

BAYÓN, F. (dir.) (1999): 50 años del turismo español. Madrid, Centro de Estudios Ramon Areces-Escuela Oficial de Turismo.

Bote Gómez, V. (1988): Turismo en espacio rural: Rehabilitación del patrimonio sociocultural y de la economía local. Ed. Popular, Madrid, 129 pp.

Bote GómeZ, V.(1990): Planificación económica del Turismo. Editorial Trillas.

Bote GómEZ, V. (1994): «Conservación de los recursos turísticos en el espacio rural». En Boletín del MAPA, 14, pp. 6-13.

Bote Gómez,V. y MARCHENA, M. (1996): «Política turística», en A. PEDREÑO (dir): Introducción a la Economía del Turismo en España, Madrid, Editorial Civitas,pp.295-326.

BUTLER, R.W. (1991). «Tourism, enviroment and sustainalble development», Enviromental Conservation, 18 (3), 201-209.

BEDOYA, J. (1998): «Turismo verde. Nuestros parques nacionales» $1^{\text {a }}$ parte, $A i$ re Libre, 59, pp.24-32.

BUCKLEY, R. y PANNELL, J. (1990): «Evironmental impacts of tourism and recreation in national parks and conservation reserves», Journal of Torurisme Studies, 1 (1),24-32.

BRAGG, L. (1990): «Ecotourism: a working definition», Forum, 2 (2), 7-12.

CALABUIG, J. y MinISTRAL, M.(1999):Manual de geografía turística de España. Ed. Síntesis. Colección Gestión Turística. $2^{\mathrm{a}}$ Ed. Revisada. Madrid. 489 pp.

CAMISÓN, C.,(1996): «Total Quality Management in Hospitality Business: an Application of the EFQM Model» Tourism Management, 17(3),191-201

CASTELlS, M. (1997): La era de la información. Economía, sociedad y cultura. Vol. 1. "La Sociedad Red". Alianza Editorial.1997, 590 pp.

CeBallos-Lascurain, H. (1992): «Tourism, ecotourism and protected areas: national parks and protected areas», en Actas de los Seminarios de la Unión Internacional para la Conservación de la Naturaleza y los Recursos Naturales, IV Congreso sobre Parques Nacionales y Zonas Protegidas, Caracas, Venezuela, 10 al 12 de Febrero, pp.84-89. 
COMISIÓN Mundial PARA El MEDIO AMBIENTE y DESARROLlo (1987): Our common future (El Informe de la Comisión Brundtland), Edición Australiana, Oxford University Press, Melbourne.

COMISIÓN DE LA UNIÓN MUNDIAL PARA LA CONSERVACIÓN DE LA NATURALEZA Y LOS RECURSOS NATURALES SOBRE PARQUES NACIONALES Y ESPACIOS PROTEGIDOS (1994): Parques para la vida: Plan de Acción para las áreas protegidas de Europa. Gland. Suiza y Cambridge, Reino Unido: Unión Mundial para la Conservación del a Naturaleza y los recursos Naturales (Versión española traducida y editada por ICONA en 1994).

CROSBY, A. (1994): Interpretación ambiental y turismo rural. Madrid, CEFAT.

CROSBY, A. (1996): Elementos básicos para un turismo sostenible en áreas rurales. Madrid. CEFAT.

Crosby, A. y MoredA, A. (1996): Desarrollo y gestión del turismo en áreas rurales y naturales. Madrid. CEFAT.

DANN, G. (1981): «Tourist motivation: an appraisal», Annals of Tourism Research, 4,184-194.

DE LUCIO, J. V. (1995): «Uso turístico de los espacios naturales protegidos». En Congreso de Turismo Rural y Turismo Activo. Presentación.pp. 215-223. Ávila.

DE LuCIO, J.V (1996): «Uso turístico de los espacios naturales protegidos». En Turismo Rural y Activo.pp.215-233 (CL) Junta de Castilla y León. Consejería de Comercio, Industria y Turismo.

DEL REGUERO OXINALDE, M. (1994): Ecoturismo: nuevas formas de turismo en el espacio rural. BosCH, Casa Editorial, Barcelona, $307 \mathrm{pp}$.

DiPUTACIÓN PROVINCIAL DE SEGOVIA (1993): Actas del I Encuentro Iberoamericano sobre municipio y turismo rural en Segovia. 1,2 y 3 de Diciembre de 1993. Ed. Diputación Provincial de Segovia. 1994.

El País-Aguilar (2002): Guía de Turismo Activo de España.Ed. El País Aguilar.

El País-Aguilar (2003): Guía de Turismo Activo de España.Ed. El País Aguilar.

El PAís (SUPLEMENTO NeGOCIOS): «El nuevo turismo gana terreno» (pp.1) y «El otro lado del sol y la playa» pp. 5 y 6.Domingo, 22 de Mayo de 2005. http//: www.elpais.es/suple/negocios

EAGLES, P. (1994):«Understanding the market for sustainable tourism», ponencia presentada en el Congreso Nacional Anual de la Asociación de Actividades Recreativas y Parques, Minneapolis, Minessota, Estados Unidos, 11 al 15 de Octubre.

FAYOS, E. (1993): «El turismo como Sector Industrial: La Nueva Política de Competitividad», Economía Industrial, Ministerio de Industria, Comercio y Turismo, Spain. 
FAYOS, E. (1994): Conference on Eurotourism. Research and perspectives, organised by the Comisión of the European Union (General Directory XXIII), Greece, 15-16 May.

FERNÁNDEZ-SAÑUDO, P. y DE LUCIO, J.V. (1995): «Desarrollo del concepto de parque natural en España». En ESPARC-95. Actas del I Seminario de Espacios Naturales Protegidos, 88-91 (CL).Sección del Estado Español de la Federación de Parques Naturales y Nacionales de Europa. Madrid.

FUENTES GARCÍA, R. (1995): El Turismo Rural en España. Especial referencia al análisis de la demanda. Serie Libros sobre Turismo, $\mathrm{n}^{\circ} 4$. Ministerio de Comercio y Turismo.

FURIÓ BLASCO, E. (1996): Economía, turismo y medio ambiente. Universidad de Valencia. 1996.

GABILONDO GARCIA DEL BARCO, E. (1996): «Turismo y medio ambiente en la provincia de Málaga: evolución y perspectivas» en El sector turístico en la provincia de Málaga, Málaga, Excma.Diput. Prov. y Colegio de Economistas de Málaga, pp. 73-111.

GODFREY-SMITH, W. (1980): «The value of wilderness: a philosophical approach», en Wilderness management in Australia (R.W. ROBERTSON, P.Helman y A. DAVey -eds.-), Actas del Simposio en el Colegio de Educación Avanzada de Canberra, 19 al 23 de Julio, Colegio de Educción Avanzada, Canberra, pp.56-71.

GómEZ LiMÓN, J., MúGiCA, M. y DE LuCIO, J. V. (1996): Uso recreativo de los espacios naturales en Madrid. Frecuentación, características de los visitantes e impactos ambiéntales (L). Serie Documentos del Centros de Investigaciones Ambientales de la Comunidad de Madrid. Fernando Gonzalez Bernáldez, $\mathrm{n}^{\circ} 19$. Consejería de Medio Ambiente y Desarrollo Regional. Madrid. 74 pp.ISBN 84-89198-23-3

GÓMEZ PRIETO, J. y GONZALEZ QUIJANO, C. (2000): Rutas e itinerarios turisticos en España. Ed. Síntesis.Madrid.

GORMSEM, E. (1981): «The spatio temporal development of international tourism: attempt acentre-periphery model» en La Consommation d'space par le Tourisme et sa Preservation, Aix-en-Provence, C.H.E.T, pp.150-170.

JUNTA DE CASTILLA Y LÉON. (1995): Actas del Congreso de Turismo rural y turismo activo. Ávila (31 de Marzo, 1 y 2 de Abril de 1995).

LEADER (1996): «El turismo ¿una oportunidad de desarrollo para las regiones desfavorecidas?». Comercializar un turismo rural de calidad: la experiencia LEADER I. Bruselas: Observatorio Europeo de Innovación y Desarrollo Rural.

LOPEZ MONNË, R. (Coord.): Turismo y planificación del territorio en la España de fin de siglo.Actas de las $\mathrm{V}$ jornadas de geografía del Turismo.Grup 
Déstudis Turístics. Unitat de Geografía. Universitat Rovira i Virgili. Tarragona.1998.435 págs.

LOVELEOCK, J. (1988): The ages of GAIA. Oxford University Press. Nueva York

LOVELOCK, J. (1993): Las edades de Gaia. Una biografia de nuestro planeta vivo. Barcelona. Tusquets.

LOZATO GIOART, J.P. (1990): Geografia del Turismo. Del espacio contemplado al espacio consumido.Ed. Masson SA.179 págs.

LUCAS, R.(1984): «The role of regulations in recreation management» Western Wildlands,9 (2),6-10

MARChENA, M.(1992): A propósito de Sevilla (Expo)'92.

MARTíNEZ, J. y SOLSONA, M.J. (2000): Alojamiento túrístico rural. Gestión y comercialización. Ed. Síntesis. Madrid

MAYO, E. y JARVIS, L. (1981): The ppsychology of leisure travel, Confederación de la Industria Británica, Boston.

Ministerio de AgRiCUlTURA, PESCA Y ALIMENTACIÓN (1992): El turismo rural en el desarrollo local. Laredo, del 22 al 26 de julio de 1991.

MúGICA, M. y DE LUCIO, J.V. (1995): «Uso de las áreas recreativas en espacios naturales de los entornos metropolitoanos». Espacios naturales en áreas metropolitanas y periurbanas. pp. 207-213. II Simposium Parque Natural de Collserola. Barcelona (A)

MuNDY, J. (1998): Leisure education: Theory and practice (2nd edition). Champaign, Illinios: Sagamore Publishing.

NAESS, A. (1988): «La ecología profunda y las premisas fundamentales», The Ecologist, 18 (4/5), 1988,128-31.

NASH, R. (1989): The right of nature, Primavera Press, Sydney, Australia.

NEIL, J. y WEARING, S. (1999): Ecoturismo: impacto, tendencias y posibilidades.Ed. Síntesis. Madrid.263pp.

ORGANIZACIÓN MUNDIAL DEL TURISMO (1998): Introducción al Turismo. Madrid.392 páginas.

ORGANIZACIÓN MUNDIAL DEL TURISMO (1990). Tourism to the year 2000, Madrid.

PELleJero MARTíneZ, C. (dir.) (1999): Historia de la economía del turismo en España. Madrid. Editorial Civitas.

PÉREZ De LAS HeRAS, M. (1999): La Guía del Ecoturismo o cómo conservar la naturaleza a través del turismo. Madrid. Ediciones Mundi-Prensa.

Poon, A. (1993): Tourism, Technology and Competitive Strategies, CAB, Oxford.

SALVADOR INSÚA, J.A. (coord..): La práctica del turismo activo deportivo en los parques naturales de Castilla y León: una posibilidad para el desarrollo 
socio-económico del mundo rural. Consejería de Cultura y Turismo. Junta de Castilla y León.2003. Inédito.

UNIÓN INTERNACIONAL EN PRO DE LA CONSERVACIÓN DE LA NATURALEZA (1985): United Nations list of national parks and protected areas, Gland, Gstaad.

VALENTINE, P.S. (1991): «Nature-based tourism: a review of prospects and problems», en Proceedings of the 1990 Congress on coastal and marine tourism - a symposium and workshop on balancing conservation and economic development (M.L.Miller y J. Auyong (eds.), Instituto Nacional de Desarrollo e Investigación sobre Recursos Costeros, Newport, Oregón.

VERA, F. (coord.) (1997): Análisis territorial del turismo.Ed. Ariel Geografía. Barcelona. 416 pp.

VERA, J. y LÓPEZ, F.: «Espacios y destinos turísticos» en GIL A. y GÓMEZ MendOZA, J: Geografía de España. Ariel Geografía. Barcelona 2001. pp. 545-571.

WiGHT, P. (996): «North American Ecotourist: market profile and trip characteristics», Journal of Travel Research, 34 (4), 2-10.

WiLliams, P. (1990): «Ecotourism management challenges», en Fifth Annual Travel Review Conference Proceedings 1990: A Year of Transition, Revista de viaje, Washington, DC.

WORLD TOURISM ORGANIZATION (1993): Sustainable Tourism Development: Guide for Local Planners. Madrid. Traducción en español: Desarrollo Turístico Sostenible. Guía para planificadores locales.

WORLD TOURISM ORGANIZATION (1997): Lo que todo gestor turístico debe saber. Madrid.

\section{ENLACES DE INTERÉS.}

http//:www.europarc.org 
Cuadro 1. Elementos esenciales del ecoturismo

El ecoturismo fomenta la comprensión de los impactos del turismo sobre el entorno natural, cultural y humano.

El ecoturismo asegura una distribución equitativa de los beneficios y los costes.

El ecoturismo genera empleo en el ámbito local, tanto de forma directa en el sector turístico como en diversos sectores de apoyo y de gestión de los recursos.

El ecoturismo representa un estímulo para el desarrollo de las industrias de la zona que producen beneficios - los hoteles y otras instalaciones de alojamiento, los restaurantes y otros establecimientos donde se sirven comidas, los sistemas de transporte, la artesanía y los guías.

El ecoturismo genera un movimiento de reservas de divisas hacia el país y supone una inyección de capital y una nueva fuente de recursos económicos para la industria local.

El ecoturismo diversifica la economía local, en particular en las zonas rurales, en las que el empleo agrícola puede ser esporádico o insuficiente.

El ecoturismo persigue el objetivo de desarrollar la capacidad de decisión entre todos los segmentos de la sociedad, incluidas las comunidades locales con el objetivo de que puedan coexistir el turismo y otros usos de los recursos. Incorpora los aspectos de planificación y división en zonas (zonación), que garantizan un desarrollo turístico en consonancia con la capacidad de carga del sistema.

El ecoturismo incentiva las mejoras en los medios de transporte, el sistema de comunicaciones y otras infraestructuras esenciales en el ámbito local.

El ecoturismo genera la aparición de instalaciones recreativas que pueden ser utilizadas tanto por las comunidades locales como por los visitantes nacionales e internacionales. También estimula y contribuye a financiar la conservación de enclaves arqueológicos, así como los edificios y los distritos urbanos de valor histórico.

El turismo de naturaleza estimula el uso productivo de tierras consideradas marginales desde el punto de vista agrícola, haciendo posible que grandes extensiones permanezcan cubiertas de vegetación natural.

El turismo cultural estimula la autoestima entre la comunidad local y proporciona la oportunidad para que exista un mayor entendimiento y comunicación entre grupos de población de orígenes diversos.

El turismo ecológicamente sostenible demuestra la importancia de los recursos naturales y culturales para el bienestar económico y social de una comunidad y puede ayudar en la conservación de dichos recursos.

El ecoturismo controla, evalúa y gestiona los impactos producidos por el turismo, desarrolla métodos fiables de contabilidad ecológica, y contrarresta cualquier efecto negativo.

FUENTE: Adaptación de material procedente de la Conferencia Globo 90. El Torrente del Turismo, Estrategia de Acción adoptada en Vancouver. Columbia Británica. Canadá. 